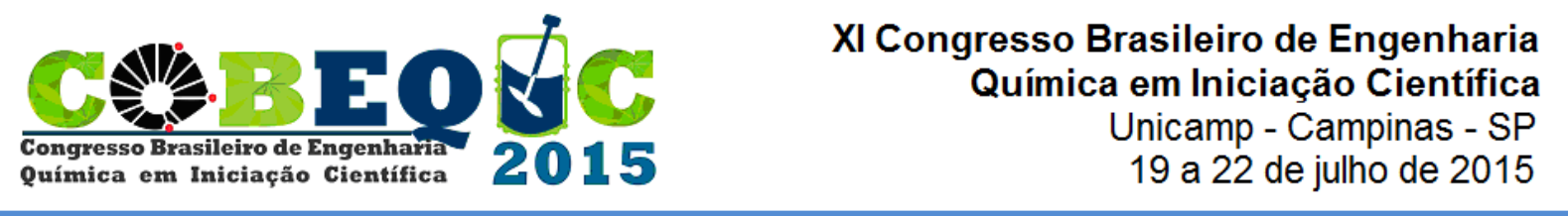

\title{
FATTY ACIDS PROFILE OF CHIA OIL-LOADED LIPID MICROPARTICLES
}

\author{
M. F. SOUZA ${ }^{1}$, J. L. SANCHEZ ${ }^{2}$, P. VALDERRAMA², E. BONA², A. A. C. TANAMATI ${ }^{1}$, \\ F. V. LEIMANN ${ }^{2}$, O. H. GONÇALVES ${ }^{2 *}$ \\ 1 Universidade Tecnológica Federal do Paraná, Departamento de Alimentos \\ ${ }^{2}$ Universidade Tecnológica Federal do Paraná, Programa de Pós-Graduação em Tecnologia \\ de Alimentos \\ *odinei@utfpr.edu.br
}

\begin{abstract}
Encapsulation of poly unsaturated fatty acid (PUFA) is known to be an alternative to increase its stability during processing and storage. Chia (Salvia hispanica L.) oil has raised interest as a reliable source of both omega-3 and omega- 6 but its encapsulation must be better evaluated. In this work, chia oil was extracted and encapsulated in stearic acid microparticles by the hot homogenization technique. UV-Vis spectroscopy coupled with Multivariate Curve Resolution with Alternating Least-Squares methodology demonstrated that no oil degradation or tocopherol loss was expected to occur during the encapsulation procedure. After lyophilization, the fat acids profile of the oil loaded microparticles was determined by gas chromatography and compared to that of the in natura oil. Both omega-3 and omega- 6 were effectively encapsulated keeping the same omega-3:omega-6 ratio presented in the in natura oil.
\end{abstract}

\section{INTRODUCTION}

The choice of consuming functional foods has directed the market to offer of products containing omega-3, antioxidants and other components with high nutritional value. Chia oil have high nutritional value since most of its constituents are triglycerides with PUFA acids presented in larger proportions and omega-3 content are between 60 and 68\% (Capitani et al. 2012). However, polyunsaturated fatty acids are susceptible to oxidation (Ixtaina et al. 2011), which can lead to the reduction of nutritional value and sensory quality. Encapsulation is a promising alternative to protect PUFAs against oxidation (Salminen et al. 2013; Muchow et al. 2009). Lipid hot homogenization has been used to encapsulate PUFAs due to the high compatibility between them and the encapsulating solid matrix. However, relatively high temperatures are required and so thermal degradation of the encapsulated compound should be evaluated, which unfortunately is not reported in most of the available works in literature. The objective of this work was to encapsulate chia oil in lipid microparticles and investigate the thermal stability of chia oil in the temperature used for its encapsulation. Concentration of its main fatty acids (omega-3 and omega-6) inside the particles was determined in order to verify if both are encapsulated in the same proportions on solid matrix.

\section{EXPERIMENTAL SECTION}

\subsection{Materials}


Chia seeds were acquired from the local market. Stearic acid (Sigma-Aldrich, 99.5\%) and Tween 80 (Dinâmica, 97\%) were used as encapsulant and surfactant, respectively. Distilled water was used as continuous phase. Methanol (Isofar, 99.8\%), chloroform (Vetec, 99.5\%), ammonium chloride (Vetec, 99.5\%), KBr (Sigma-Aldrich, spectrophotometric standard) and sulphuric acid (Vetec, 95\%) were used as received.

\subsection{Chia oil extraction and quantification of degradation products by MCR-ALS}

The total moisture of the chia seeds was determined and then adjusted to $80 \%$ by adding distilled water. Then, the extraction was performed according to the methodology described by Bligh and Dyer (1959). Chia oil was stored at $-10^{\circ} \mathrm{C}$ protected from light. The quantification of oil degradation products was carried out to determine if chia oil was prone to degrade in the temperature used in the encapsulation procedure $\left(75^{\circ} \mathrm{C}\right)$. A sample of in natura chia oil were heated and aliquots were collected at $30,40,50,60,70$ e $75^{\circ} \mathrm{C}$. The sample was then kept at $75^{\circ} \mathrm{C}$ and aliquots were also collected after regular time intervals for 120 minutes. UV-Visible spectra (Ocean Optics, Red Tide USB650, $1 \mathrm{~nm}$ resolution) were obtained and the formation of degradation products was evaluated by Multivariate Curve Resolution Alternating Least-Squares method (MCR-ALS) as described by Gonçalves et al. 2014. The spectrum bands recovered by MCR-ALS were attributed to their respective compounds according to Valderrama et al. (2011).

\subsection{Microparticles production and characterization}

Chia oil-loaded microparticles were obtained by the hot homogenization technique (Gonzalez-Mira et al. 2010). The aqueous phase was prepared dissolving Tween $80(0,300 \mathrm{~g})$ in distilled water $(25 \mathrm{~g})$ and heating to $75^{\circ} \mathrm{C}$ under gentle stirring. Separately, stearic acid $(0,625 \mathrm{~g})$ was melted at $75^{\circ} \mathrm{C}$ in a borosilicate double walled vessel. Chia oil was then added to the molten lipid and mixed for 1 minute. Then, the aqueous phase was added to the vessel and stirred for 3 minutes resulting in an oil-in-water macroemulsion. Sonication (FisherScientific - Ultrasonic Dismembrator $120 \mathrm{~W}, 1 / 8$ " tip) was carried out for 3 minutes in a pulse regime ( 30 seconds on and 10 seconds off). The sonicated mixture was cooled in ice bath resulting in the formation of solid lipid particles dispersed in water. They were freeze dried before analysis. The same procedure was also carried out without the addition of chia oil to obtain blank microparticles. Fourier Transform Infrared Spectroscopy (FTIR, Shimadzu IR Affinity-1) of the lyophilized particles or in natura oil was used to qualitatively evaluate the oil loaded microparticles. Particles morphology were observed using optical microscopy (BIOVAL, L2000A) coupled to a digital camera (DCM130E). To determine the encapsulation efficiency (Equation 1), an aliquot of the microparticles dispersion was filtered (Amicon, 100 $\mathrm{kDa})$ at $14,500 \mathrm{rpm}$ for 15 minutes. The fatty acids concentration in the liquid ([FA $]_{\text {non- }}$ encapsulated) was determined by GC as described previously. The microparticles were freezedried and the total amount of fatty acids (encapsulated and non-encapsulated, [FA] total) was also determined.

$E E(\%)=100 \frac{[F A]_{\text {total }}-[F A]_{\text {non-encapsualted }}}{[A G]_{\text {total }}}$

\subsection{Transesterification and Gas Chromatography (CG)}


Fatty acids quantification was performed by CG using methyl tricosanoate (23:0) as internal standard according to Hartman and Lago methodology (Hartman and Lago 1973; Milinsk et al. 2008). Fatty acid methyl esters (FAMEs) were separated and identified by comparing with chromatograph standards (Sigma-Aldrich, F.A.M.E. Mix C14-C22). The equipment used was as follows: gas chromatograph (Shimadzu, GC-2010 Plus AF) equipped with capillary injector Split/Splitless, flame ionization detector (FID), flow and pressure automatic controllers and a 100\% dimethylpolysiloxane capillary column (Rtx-1, 30m x $0,25 \mathrm{~mm} \times 0,25 \mu \mathrm{m})$. More details of the experimental conditions can be found elsewhere (Milinsk et al. 2008). The transesterefications were performed in triplicate.

\section{RESULTS AND DISCUSSION}

\subsection{Quantification of degradation}

Figures 1 presents the data of thermal degradation of the in natura chia oil (before encapsulation) at different temperatures.

Figure 1- Relative concentration profile of tocopherol (- - - ) and dienes/trienes conjugated/hydrolysis products (-) of in natura chia oil (before encapsulation): (a) at
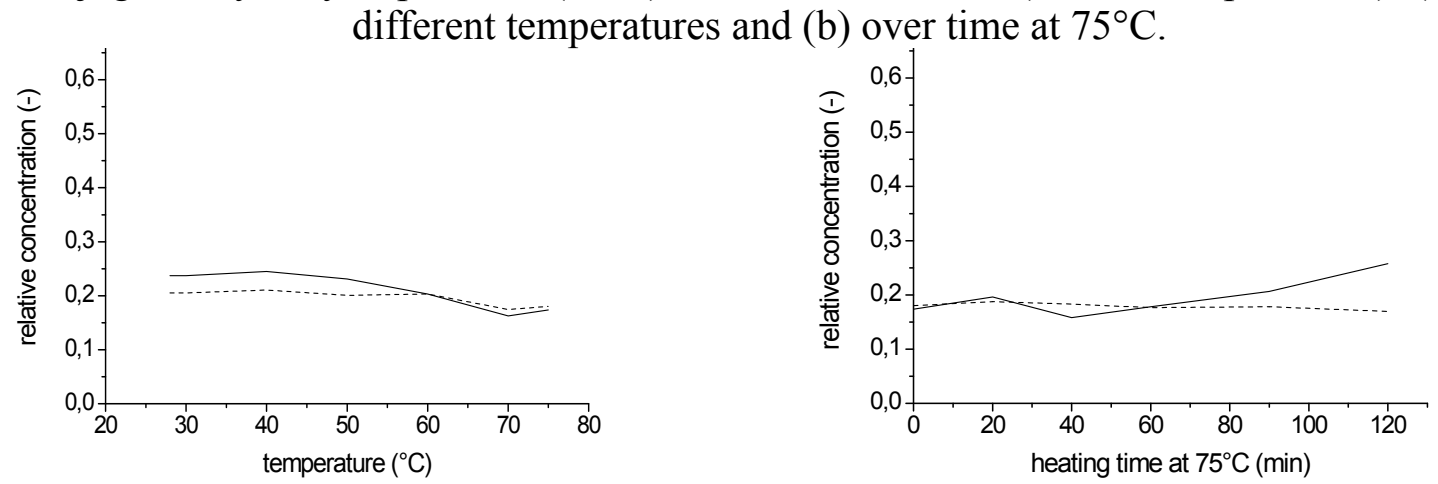

It is worth noting that thermal degradation is a concern because the hot homogenization technique requires relatively high temperature and chia oil is rich in unsaturated fatty acids. Recuperated spectra showed the presence of tocopherol as expected (Ixtaina et al. 2011) and that its concentration started to decreased only when the sample was heated to $75^{\circ} \mathrm{C}$ for 2 hours. The formation of degradation compounds such as conjugated dienes and trienes and hydrolysis products was also detected only after heating to $75^{\circ} \mathrm{C}$ for 2 hours. Gonçalves et al. (2014) demonstrated that the formation of degradation products, the disappearance of the tocopherol and the temperature in which degradation begins are highly dependent on the oil composition and origin. In the encapsulation procedure proposed in this work, chia oil remained at $75^{\circ} \mathrm{C}$ for approximately 7 minutes. These results strongly indicate that on appreciable thermal degradation of the chia oil is expected to takes place during its microencapsulation and that the proposed procedure can be safely used to encapsulate chia oil without losing its nutritional properties.

\subsection{Chia Oil Encapsulation}

The chromatograms of the chia oil before encapsulation (in natura) are presented in Figure 2. Figure 3 presents the fatty acids profile of the lyophilized oil-loaded microparticles and Figure 4 presents the fatty acids profile of the non-encapsulated oil. Both are compared to the in natura chia oil. 


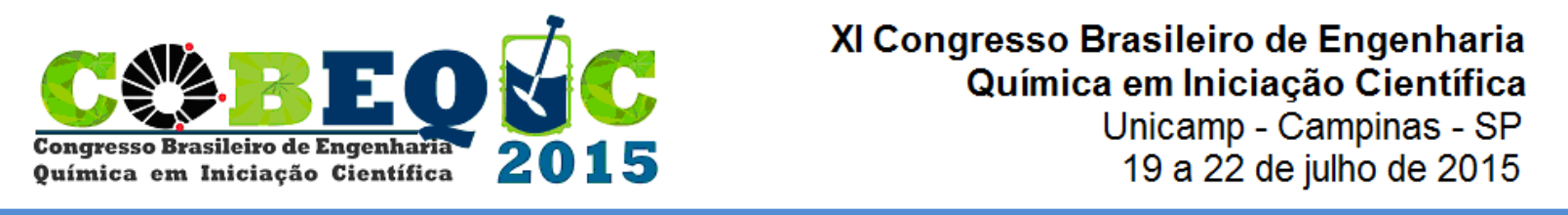

Figure 2 - Chromatogram of in natura chia oil (before encapsulation).

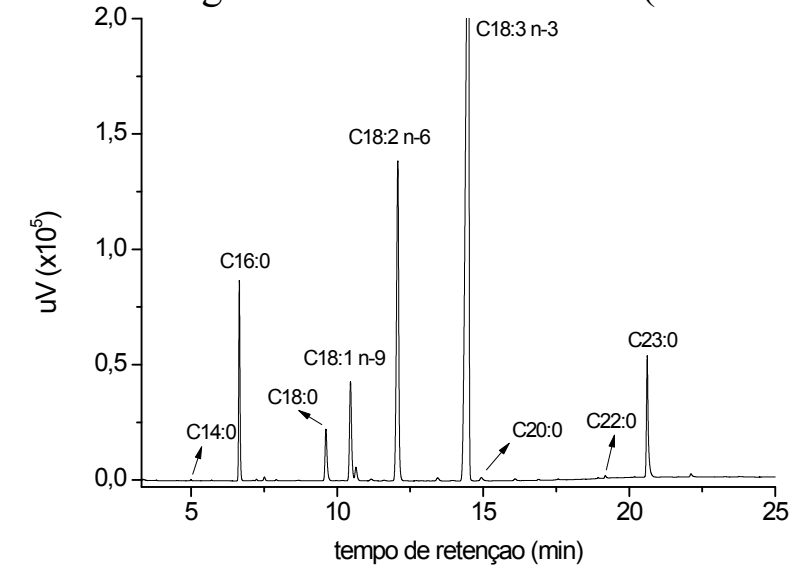

Figure 3 - Chromatograms of in natura chia oil (red) and oil-loaded microparticles (free + encapsulated oil) (black).

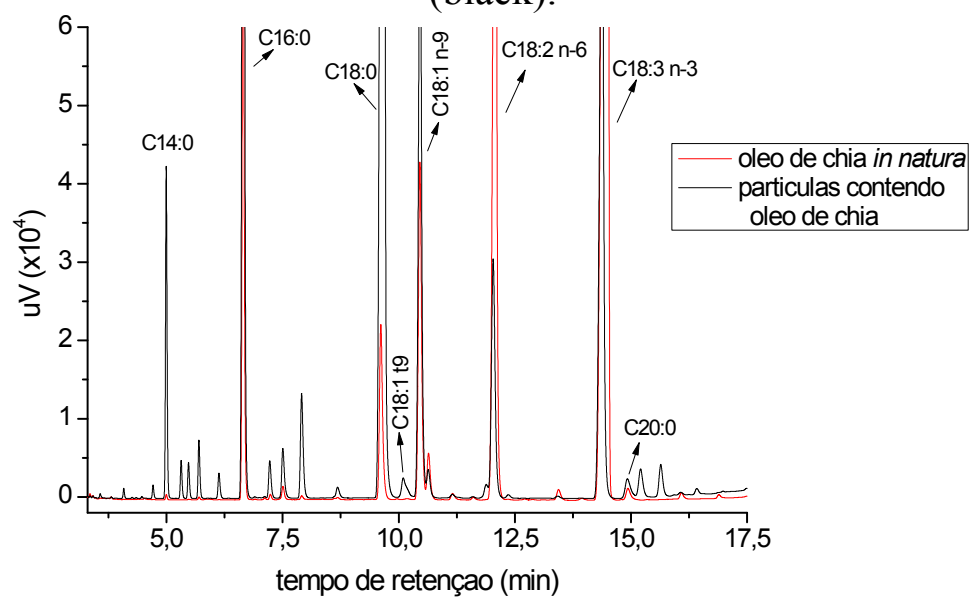

Figure 4-Chromatograms of the non-encapsulated (free) chia oil (red) and particles containing chia oil encapsulated (black).

Oil extraction from the chia seeds resulted in a yield of $19.8 \mathrm{wt} \%$. Bligh-Dyer is a suitable technique to extract unsaturated fatty acids because no heat is required and a wild range of lipids can be extracted. It is possible to observe in Figure 1 the peaks correspondent to linoleic acid (omega-6) and alpha-linolenic (omega-3) at retention times of approximately 12 and 14 minutes, respectively. As expected, chia oil is a valuable source of omega-3 and 6. The total omega-3 and omega- 6 concentration found were $(565.52 \pm 24.4)$ and $(181.94 \pm$ $5.75) \mathrm{g} / 100 \mathrm{~g} \mathrm{FA}$, which is in accordance with the literature (Capitani et al. 2012). It is possible to observe (Figure 3) that omega-3 and 6 were presented in the microparticles, however both peaks are less pronounced due to the presence of the encapsulant (stearic acid). The chromatogram of the oil-loaded microparticles (Figure 4) presented a well pronounced peak related to stearic acid $(\mathrm{C} 18: 0)$ as well as other small peaks corresponding to impurities. High encapsulation efficiencies were found for omega-3 and 6 meaning that the hot homogenization technique is indicated to encapsulate these compounds.

Encapsulation efficiency of omega-3 and omega- 6 were $(95.4 \pm 0.6)$ and $(92.3 \pm 1.9) \%$ respectively. No significant difference was detected between the encapsulation efficiency of omega-3 and omega- $6(\mathrm{p}<0.05)$, therefore the omega-3:omega- 6 ratio found for in natura oil $(3.11 \pm 0.05)$ was maintained after encapsulation $(3.14 \pm 0.14)$ at a significance level of $95 \%$.Encapsulation of liquid lipids in solid lipid matrices is expected to be greater than the obtained by other methods due the inherent compatibility between encapsulant and the encapsulated compound. Lacatusu et al. (2013) obtained encapsulated fish oil in 
nanostructure lipid carriers finding an efficiency of $88.5 \%$. However, several authors do not present encapsulation efficiency in their works, probably assuming maximum values (Salminen et al. 2013; Muchow et al. 2009), which could lead to erroneous conclusions. Encapsulation of omega-3 and 6 rich oils by spray drying are $70-80 \%$ (Rodea-González et al. 2012).

\subsection{Microparticles Characterization}

Figure 5 and 6 present optical microscopy images of the blank microparticles (no chia oil added) and chia oil-loaded microparticles, respectively. Figure 7 presents the infrared spectra of in natura chia oil, blank microparticles and chia oil-loaded microparticles (spectra were normalized in order to enable the comparison).

Figure 5-Optical microscopy image of the blank microparticles.

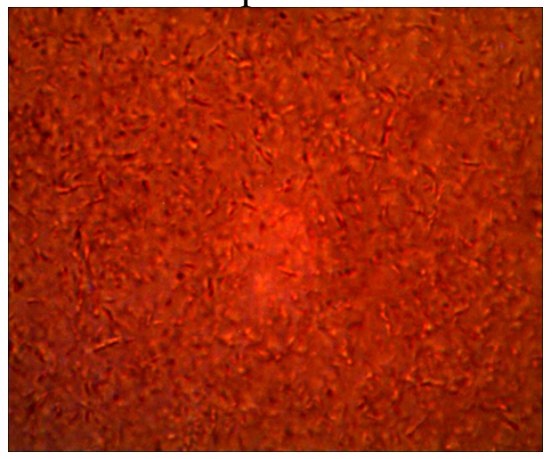

Figure 6 -Optical microscopy image of oil-loaded microparticles.

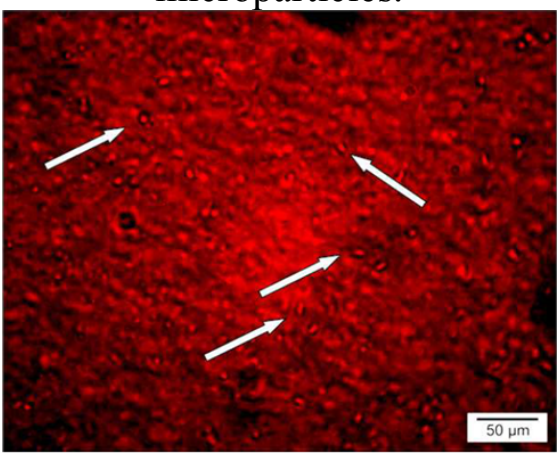

Figure 7 - FTIR spectra of in natura chia, blank microparticles and chia oil-loaded microparticles.

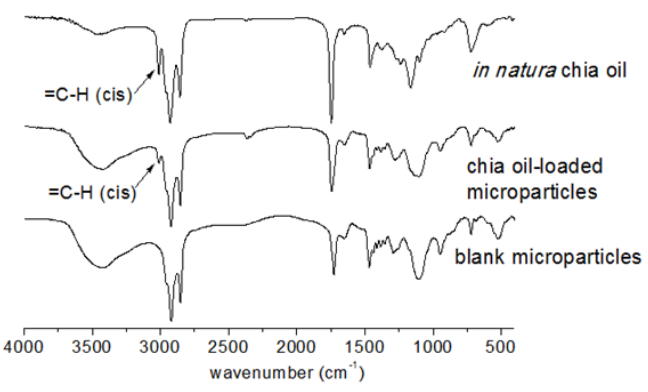

Microparticles presented diameters of about 5 to 10 micrometers, which was expected due to the low sonication time and potency applied. In the case of blank microparticles, spikelike morphology was formed which is characteristic of the stearic acid $\alpha$-phase. Microparticles containing chia oil presented spherical morphology indicating that the solid lipid matrix was plasticized by the chia oil and that $\beta$-phase was formed. The comparison between both morphologies suggested that chia oil was effectively encapsulated, thus corroborating the Gas Chromatography analyses. The FTIR spectra of in natura chia oil presented the $=\mathrm{C}-\mathrm{H}$ stretching band at $3010 \mathrm{~cm}^{-1}$. This band is of interest because it is not presented by the encapsulant. The same band is presented by the oil-loaded microparticles but with lower intensity suggesting that the oil located inside the stearic acid particles. This blinding effect is known to occur in other encapsulated systems (CIT).

\section{CONCLUSIONS}

Chia oil was extracted using the Bligh \& Dyer method (no heating required) with the following properties: $19.8 \mathrm{wt} \%$ yield, total omega-3 concentration of $565.52 \pm 24.4 \mathrm{~g} / 100$ gFA and omega 3:omega 6 ratio of $(3.11 \pm 0.05)$. Multivariate Curve Resolution demonstrated that the chia oil did not presented degradation of tocopherol at the temperature and time used in the microcapsules production $\left(75^{\circ} \mathrm{C}\right.$ for 7 minutes). The oil was encapsulatd in stearic acid forming spheric microparticles (5-10 micrometers). Gas Chromatography demonstrated that the oil was effectively encapsulated in the microparticles and this result was also corroborated by the particles morphology and FTIR analysis. Encapsulation efficiency was high for both ômega-3 and ômega-6 keeping the ômega 3:ômega 6 relation presented by the in natura oil. 


\section{REFERENCES}

BLIGH, E. G.; DYER, W. J. A Rapid Method of Total Lipid Extraction and Purification. Canadian Journal of Biochemistry and Physiology 37 (8): 911-17, 1959.

CAPITANI, M. I.; SPOTORNO, V.; NOLASCO, S. M.; TOMÁS, M. C. Physicochemical and functional 124 characterization of by-products from chia (Salvia hispanica L.) seeds of Argentina. LWT - Food Sci. Technol. v. 45, n. 1, p. 94-102, 2012.

GONÇALVES, R. P; MARÇO, P. H.; VALDERRAMA, P. Thermal Edible Oil Evaluation by UV-Vis Spectroscopy and Chemometrics. Food Chemistry 163 (November): 83-86, 2014.

GONZALEZ-MIRA, E.; EGEA, M. A.; GARCIA, M. L.; SOUTO, E. B "Design and Ocular Tolerance of Flurbiprofen Loaded Ultrasound-Engineered NLC." Colloids and Surfaces. B, Biointerfaces 81 (2). Elsevier B.V.: 412-21, 2010.

HARTMAN, L.; LAGO, R. C. A. Rapid preparation of fatty acid methyl from lipids. Lab. Pract. V. 22, p. 474-131 476, 1973.

IXTAINA, V. Y.; MARTÍNEZ, M.. L.; SPOTORNO, V.; MATEO, C. M.; MAESTRI, DAMIÁN, M.; DIEHL, B. W. K.; NOLASCO, S. M.; TOMÁS, M. C. Characterization of chia seed oils obtained by pressing and solvent 134 extraction. J. Food Compos. Anal. v. 24, n. 2, p. 166-174, Mar. 2011.

LACATUSU, I.; MITREA, E.; BADEA, N.; STAN, R.; OPREA, O.; MEGHEA, A. Lipid Nanoparticles Based on Omega-3 Fatty Acids as Effective Carriers for Lutein Delivery. Preparation and in Vitro Characterization Studies. Journal of Functional Foods 5 (3). Elsevier Ltd: 1260-69, 2013.

MILINSK, M. C.; MATSUSHITA, M.; VISENTAINER, J. V.; OLIVEIRA, C. C.; SOUZA, N. E. de . Comparative Analysis of Eight Esterification Methods in the Quantitative Determination of Vegetable Oil Fatty Acid Methyl Esters (FAME). Journal of the Brazilian Chemical Society 19 (8): 1475-83, 2008.

MUCHOW, M.; SCHMITZ, E. I.; DESPATOVA, N.; MAINCENT, P.; MÜLLER, R. H. Omega-3 Fatty Acids-Loaded Lipid Nanoparticles for Patient-Convenient Oral Bioavailability Enhancement. Pharmazie 64: 499-504, 2009.

RODEA-GONZÁlEZ， D. A.; CRUZ-OLIVARES， J.; ROMÁN-GUERRERO, A.; RODRÍGUEZ-HUEZO, M. E.; VERNON-CARTER, E. J.; PÉREZ-ALONSO, C. SprayDried Encapsulation of Chia Essential Oil (Salvia Hispanica L.) in Whey Protein Concentrate-Polysaccharide Matrices." Journal of Food Engineering 111 (1): 102-9, 2012.

SALMINEN, H.; HELGASON, T.; KRISTINSON, B.; KRISTBERGSSON, K.; WEISS, J. Formation of Solid Shell Nanoparticles with Liquid $\Omega-3$ Fatty Acid Core. Food Chemistry 141 (3). Elsevier Ltd: 2934-43, 2013.

VALDERRAMA, P.; MARÇO, P.H.; LOCQUET, N.; AMMARI, F.; RUTLEDGE, D. N. A Procedure to Facilitate the Choice of the Number of Factors in Multi-Way Data Analysis Applied to the Natural Samples: Application to Monitoring the Thermal Degradation of Oils Using Front-Face Fluorescence Spectroscopy. Chemometrics and Intelligent Laboratory Systems 106 (2). Elsevier B.V.: 166-72, 2011. 